\title{
Capillaria spp. eggs in Patagonian archaeological sites: statistical analysis of morphometric data
}

\author{
Martín H Fugassa ${ }^{+}$, Verónica Taglioretti ${ }^{1}$, Marcelo LC Gonçalves ${ }^{2}$, Adauto Araújo ${ }^{3}$, \\ Norma H Sardella, Guillermo M Denegri
}

Laboratorio de Zoonosis Parasitarias, ${ }^{1}$ Facultad de Ciencias Exactas y Naturales, Universidad Nacional de Mar del Plata, calle Funes 3350, Mar del Plata, Buenos Aires, Argentina ${ }^{2}$ Universidade de Fortaleza, Fortaleza, Brasil ${ }^{3}$ Escola Nacional de Saúde Pública-Fiocruz, Rio de Janeiro, Brasil

Discriminant analysis was used to identify eggs of Capillaria spp. at specific level found in organic remains from an archaeological site in Patagonia, Argentina, dated of 6,540 \pm 110 years before present. In order to distinguish eggshell morphology 149 eggs were measured and grouped into four arbitrary subsets. The analysis used on egg width and length discriminated them into different morphotypes (Wilks' lambda $=0.381, p<0.05$ ). The correlation analysis suggests that width was the most important variable to discriminate among the Capillaria spp. egg morphotypes (Pearson coefficient $=0.950, p<0.05$ ). The study of eggshell patterns, the relative frequency in the sample, and the morphometric data allowed us to correlate the four morphotypes with Capillaria species.

Key words: paleoparasitology - coprolites - Capillaria - discriminant analysis

Capillaria spp. eggs have been recovered in human coprolites and latrine sediments from Old World archaeological sites (Bouchet et al. 2003, Dittmar \& Teejen 2003, Fernandes et al. 2005). Human capillariosis is rarely found today, but in some places of the world it is a public health problem, such as in Philippines, where Capillaria philippinensis infection is endemic. Eggs of Capillaria spp. were also found in South American Indian populations (Coimbra \& Mello 1981).

Capillaria putorii and occasionally Capillaria erinacea were found in omnivorous animals (Soulsby 1987, Gomper et al. 2003). In wild canids, Capillaria aerophila was found infecting the respiratory tract (Soulsby 1987) and, in South America, Capillaria plica was found in kidneys and Capillaria hepatica in liver tissues of autopsied jackals (Ruas et al. 2003).

Morphometric parameters of nematode eggs are a very useful tool to identify intestinal parasites (Benbrook \& Sloos 1965). They can be also applied to distinguish Capillaria species. In the genus Capillaria, different aspects of the eggshell structure may be used as a taxonomic clue (Moravec 2001).

In a previously paleoparasitological study in Argentina, 149 well-preserved Capillaria spp. eggs were found in a coprolite supposed to be from a canid, dated 6,540 \pm 110 years Before Present (Fugassa et al. 2006). Capillaria species and the ecopathological context related to this coprolite, a very rich sample in Capillaria spp. eggs, were studied here.

The 149 eggs were measured and grouped into four arbitrary subsets according to distinct eggshell morphology, as follows: morphotype A (large eggs with shallow

Financial support: FONCyT PICT 4-13889, CAPES/SECyT BR/PA05/HIV/017-002/05, CNPq and FONCyT-UNMdP PICTO 4-849

+ Corresponding author: mfugassa@mdp.edu.ar

Received 29 August 2007

Accepted 15 February 2008 polar plugs and radial striations), morphotype B (wide eggs with prominent polar plugs and longitudinal striations), morphotype C (eggs with pitted surface), and morphotype D (eggs with irregular striations and short plugs) (Fig. 1). The morphometric parameters of each morphotype are shown in Table.

It was evaluated if morphometric differences were related to the morphotypes, if the differences among the morphotypes were significant, and if any linear combination of the predictor variables length and width that could provide the best discrimination between egg morphotypes through discriminant analysis (Legendre \& Legendre 1998). Discriminant analysis is used to build a predictive model of group membership based on observed characteristics of each case. This procedure generates a discriminant function based on linear combinations of the predictor variables that provide the best discrimination between the groups analyzed. Statistical analyses were performed using the SPSS package.

The eggs of Capillaria spp. examined exhibited very variable sizes, as well as a high variability in the eggshell patterns and operculum characteristics. The results from the discriminant analysis using egg width and length discriminated the eggs found into the different morphotypes (Wilks' lambda $=0.419, \mathrm{p}<0.05$, Fig. 2). The correlation analysis between the explanatory variables and discriminant functions 1 and 2 suggests that width was the most important variable in the discrimination among the Capillaria spp. egg morphotypes (Pearson coefficient $=0.963, \mathrm{p}<0.05)$. As it can be seen in Fig. 2, the major variability between groups is observed in the discriminant axis X (function 1), so this axis represents the best linear combinations of the predictor variables in explaining the diferences found among the groups.

The study of eggshell patterns, the relative frequency of the eggs in the sample, and the morphometric data allowed us to correlate the four morphotypes with some species of Capillaria. 


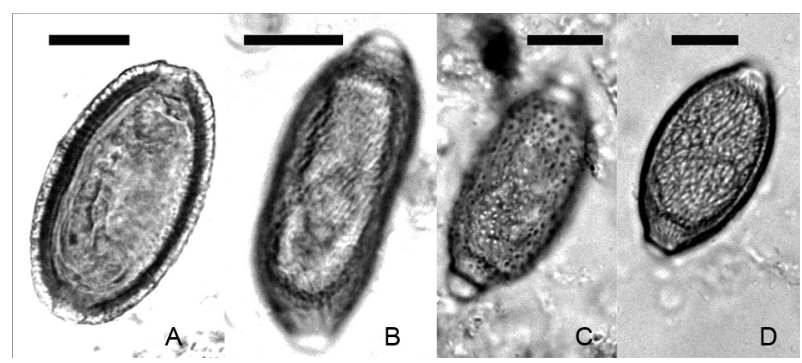

Fig. 1: different morphotypes (A, B, C, and D) found among Capillaria eggs. Scale bar $=20 \mu \mathrm{m}$.

TABLE

Morphometric parameters of the four morphotypes of Capillaria spp. eggs identified

\begin{tabular}{lcccccccc}
\hline & & & \multicolumn{2}{c}{ Lenght $(\mu \mathrm{m})$} & & \multicolumn{2}{c}{ Width $(\mu \mathrm{m})$} \\
Morphotype & $\mathrm{n}$ & $\%$ & Mean & Range & & Mean & Range \\
\hline A & 20 & 13.4 & 63.7 & $57.5-75.0$ & & 38.1 & $33.8-41.3$ \\
$\mathrm{~B}$ & 85 & 57.0 & 59.8 & $42.5-67.5$ & & 28.8 & $22.5-37.5$ \\
$\mathrm{C}$ & 19 & 12.8 & 62.1 & $40.0-71.3$ & & 32.7 & $27.5-37.5$ \\
$\mathrm{D}$ & 25 & 16.8 & 54.2 & $42.5-72.5$ & & 29.3 & $22.5-47.5$ \\
\hline
\end{tabular}

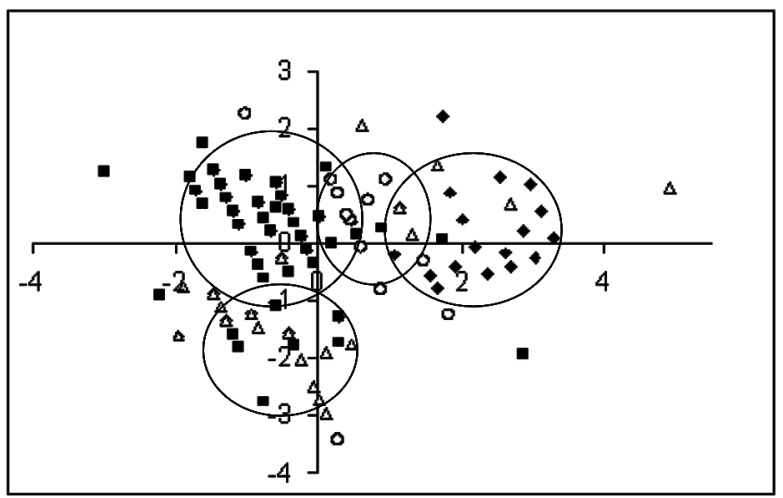

Fig. 2: plot of the discriminant function 1 (axis $\mathrm{x}$ ) and 2 (axis $\mathrm{y}$ ) of egg morphotypes A (४), B (๘), C (०), and D ( $\Delta)$.

In morphotype A, egg sizes were compatible with $C$. hepatica eggs (Grigonis \& Solomon 1976). Eggs of this species remain in the liver parenchyma and are not excreted in feces. The relatively low number of morphotype A eggs found in the coprolite could indicate consumption of an infected prey, rather than be a case of true parasitism. Small bone fragments presumed to belong to a rodent were found in the coprolite (Fugassa et al. 2006). Morphotype B eggs probably were from $C$. putorii, due to their abundance, their sizes and distinct striation on the eggshell (Bowman et al. 2003). This species is found infecting the intestines of canids and felines. Morphotype $\mathrm{C}$ eggs were in the range of $C$. aerophila egg sizes (Benbrook \& Sloss 1965). The relatively low number of eggs found with this morphotype could be explained by the localization of the adult worms. As they reside in the respiratory tract, eggs can be released into the environment through the cough or, if swallowed by the animal, through the feces. Morphotype D eggs could not be associated to any known species of Capillaria. Probably it should be considered a distinct maturation stage of any other morphotype.

Results obtained showed a continuing history of infection by these Capillaria species in Patagonian mammals dated of 6,500 years ago (Fugassa et al. 2006), and that discriminant analysis can be an useful and reliable tool to identify species of Capillaria that are not easily identified by morphologic patterns, due to changes during taphonomic processes or to any other unknown condition. In spite of the complex taxonomy of capillarids, this article states that the combination of morphologic and morphometric analysis of Capillaria spp. eggs improves the specificity of the diagnosis in paleoparasitological studies.

\section{ACKNOWLEDGMENTS}

To Carlos Aschero and María Teresa Civalero for allowing the authors to study the archaeological material.

\section{REFERENCES}

Benbrook EA, Sloss MW 1965. Parasitología Clínica Veterinaria, Compañia Editorial Continental, México, 240 pp.

Bouchet F, Harter S, Le Bailly M 2003. The state of the art of paleoparasitological research in the Old World. Mem Inst Oswaldo Cruz 98 (Suppl. I): 95-101.

Bowman DD, Barr SC, Hendrix CM, Lindsay DS 2003. Gastro-intestinal Parasites of Cats. In DD Bowman, Companion and Exotic Animal Parasitology, International Veterinary Information Service, New York. [cited 2007 Dec 12]. Available from: http://www. ivis.org/advances/Parasit_Bowman/ddb_GI/ivis.pdf.

Coimbra Jr CEA, Mello DA 1981. Enteroparasitoses e Capillaria sp. entre o grupo indígena Suruí, Parque Indígena Aripuanã, Rondônia. Mem Inst Oswaldo Cruz 76: 299-302.

Dittmar K, Teejen WR 2003. The presence of Fasciola hepatica (liver fluke) in human and cattle from a 4,500 years old archaeological site in the Saale-Unstrut Valley, Germany. Mem Inst Oswaldo Cruz 98 (Suppl. I): 141-144.

Fernandes A, Ferreira LF, Gonçalves MLC, Bouchet F, Klein CH, Iguchi T, Sianto L, Araújo A 2005. Intestinal parasite analysis in organic sediments collected from a 16th-century Belgian archeological site. Cad Saude Publica 21: 329-332.

Fugassa MH, Denegri GM, Sardella NH, Araújo A, Guichón RA, Martinez PA, Civalero MT, Aschero C 2006. Paleoparasitological records in canid coprolite from Patagonia, Argentina. J Parasitol 92: 1110-1113.

Gompper ME, Goodman, RM, Kays RW, Ray JC, Fiorello CV 2003. A survey of the parasites of coyotes (Canis latrans) in New York based on fecal analysis. J Wildl Dis 39: 712-717.

Grigonis GJ, Solomon GB 1976. Capillaria hepatica: fine structure of egg shell. Exp Parasitol 40: 286-297.

Legendre P, Legendre L 1998. Numerical Ecology, 2nd ed., Elsevier, Amsterdam, 853 pp.

Moravec F 2001. Parasitic in Cold-blooded Vertebrates, Academia, Praha, 429 pp.

Ruas JL, Soares MP, Farias NAR, Brum JGW 2003. Infecção por Capillaria hepatica em carnivoros silvestres (Lycalopex gymnocercus e Cerdocyon thous) na região sul do Rio Grande do Sul. Arq Inst Biol (Sao Paulo) 70: 127-130.

Soulsby EJL 1987. Parasitología y Enfermedades Parasitarias de los Animales Domésticos, 7th ed., Interamericana, Mexico, 822 pp. 